Am J Prev Med. 2017 January ; 52(1): 100-105. doi:10.1016/j.amepre.2016.07.013.

\title{
A Cluster Randomized Trial of a Personalized Multi-Condition Risk Assessment in Primary Care
}

\author{
Jennifer S. Haas, MD, MSc ${ }^{1,2,3}$, Heather J. Baer, ScD ${ }^{1,2,4}$, Katyuska Eibensteiner, BA ${ }^{1}$, \\ Elissa V. Klinger, ScM ${ }^{1}$, Stella St. Hubert, AB $^{1}$, George Getty ${ }^{1}$, Phyllis Brawarsky, MPH ${ }^{1}$, E. \\ John Orav, PhD ${ }^{1,2,5}$, Tracy Onega, PhD $^{6}$, Anna N.A. Tosteson, ScD $^{6}$, David W. Bates, MD, \\ MSc $^{1,2,7}$, and Graham Colditz, MD, DrPH ${ }^{8}$ \\ ${ }^{1}$ Division of General Medicine and Primary Care, Brigham and Women's Hospital, Boston, \\ Massachusetts \\ ${ }^{2}$ Department of Medicine, Harvard University Medical School, Boston, Massachusetts \\ ${ }^{3}$ Department of Social and Behavioral Sciences, Harvard University School of Public Health, \\ Boston, Massachusetts \\ ${ }^{4}$ Department of Epidemiology, Harvard University School of Public Health, Boston, Massachusetts \\ ${ }^{5}$ Department of Biostatistics, Harvard University School of Public Health, Boston, Massachusetts \\ ${ }^{6}$ Dartmouth Institute for Health Policy and Clinical Practice, Geisel School of Medicine at \\ Dartmouth and Norris Cotton Cancer Center, Lebanon, New Hampshire \\ ${ }^{7}$ Department of Health Policy and Management, Harvard University School of Public Health, \\ Boston, Massachusetts \\ ${ }^{8}$ Institute for Public Health, Washington University School of Medicine, St. Louis, Missouri
}

\section{Abstract}

Introduction-Personal risk for multiple conditions should be assessed in primary care. This study evaluated whether collection of risk factors to generate electronic health record (EHR)linked health risk appraisal (HRA) for coronary heart disease, diabetes, breast cancer, and colorectal cancer was associated with improved patient-provider communication, risk assessment, and plans for breast cancer screening.

\begin{abstract}
Methods-This pragmatic trial recruited adults with upcoming visits to 11 primary care practices during 2013-2014 (N=3,703). Pre-visit, intervention patients completed a risk factor and perception assessment and received an HRA; coded risk factor data were sent to the EHR. Postvisit, intervention patients reported risk perception. Pre-visit, control patients only completed the
\end{abstract}

\footnotetext{
Address correspondence to: Jennifer S. Haas, MD, MSc, Division of General Medicine and Primary Care, Brigham and Women's Hospital, 1620 Tremont Street, Boston MA 02120. jhaas@partners.org.

Publisher's Disclaimer: This is a PDF file of an unedited manuscript that has been accepted for publication. As a service to our customers we are providing this early version of the manuscript. The manuscript will undergo copyediting, typesetting, and review of the resulting proof before it is published in its final citable form. Please note that during the production process errors may be discovered which could affect the content, and all legal disclaimers that apply to the journal pertain.

Clinical Trial Registration: NCT01468675

No financial disclosures were reported by the authors of this paper.
} 
risk perception assessment; post-visit they also completed the risk factor assessment and received the HRA. No data were sent to the EHR for controls. Accuracy/improvement of self-perceived risk was assessed by comparing self-perceived to calculated risk.

Results-The intervention was associated with improvement of patient-provider communication of changes to improve health $(78.5 \%$ vs $74.1 \%, \mathrm{AOR}=1.67,99 \% \mathrm{CI}=1.07,2.60)$. There was a similar trend for discussion of risk $(54.1 \%$ vs $45.5 \%, \mathrm{AOR}=1.34,95 \% \mathrm{CI}=0.97,1.85)$. The intervention was associated with greater improvement in accuracy of self-perceived risk for diabetes $(16.0 \%$ vs $12.6 \%, p=0.006)$ and colorectal cancer $(27.9 \%$ vs $17.2 \%, p<0.001)$ with a similar trend for coronary heart disease and breast cancer. There were no changes in plans for breast cancer screening.

Conclusions-Patient-reported risk factors and EHR-linked multi-condition HRAs in primary care can modestly improve communication and promote accuracy of self-perceived risk.

\section{Introduction}

Family health history and lifestyle contribute to risk of developing chronic diseases like diabetes, coronary heart disease, and cancer. ${ }^{1,2}$ Systematic assessment of this information may facilitate early identification of patients at greatest risk, promote informed decision making, ${ }^{3}$ and address barriers to risk assessment in practice. ${ }^{4,5}$ Use of health risk appraisals (HRAs) in primary care may promote accurate risk assessment, motivate health promotion and behavior change, and facilitate population management, ${ }^{6,7}$ particularly as recommendations for screening and prevention become more personalized. ${ }^{8}$

Electronic health records (EHRs) offer opportunities to overcome barriers to collection and synthesis of these data by integrating HRAs with EHRs. Patient Risk Evaluation and Prevention (PREP) collected family health history and lifestyle risk factors from primary care patients and produced a personalized HRA for coronary heart disease, diabetes, breast cancer (for women), and colorectal cancer. The goal was to examine whether generating an HRA for patients prior to a visit, with data transmission to an EHR for provider use, improved patient-provider communication, more accurate self-perceived risk assessment, and plans for breast cancer screening.

\section{Methods}

The PREP study was a pragmatic cluster RCT of adults receiving care in 11 practices affiliated with the Brigham and Women's Primary Care Practice Network. The protocol was IRB-approved and registered at Clinicaltrials.gov (NCT01468675).

\section{Study Population}

Eligible patients were aged 30-75 years, had an annual or new patient visit, and spoke English or Spanish. Patients were excluded who did not have a phone or e-mail address.

Randomization occurred at the practice level, with recruitment May 2013-November 2014. Patients could participate by web (55.8\%) or automated phone survey (44.2\%). Pre-visit assessment in the intervention group included questions to generate an HRA and self- 
perceived risk for each condition (Table 1). The HRA was mailed before the primary care provider (PCP) visit. Coded, health level-7 (HL7)-compliant risk factor data were sent to the EHR for use in documentation and decision support. PCPs received a data alert e-mail the morning of the visit and an icon appeared on their daily schedule next to the patient's name (Appendix A). Two to 4 weeks post-visit, intervention patients re-assessed self-perceived risk. Pre-visit, control patients only completed the risk perception assessment; post-visit they also completed the risk factor assessment and received the HRA. No data were sent to the EHR for the control group.

Your Health Snapshot is a self-administered HRA derived from validated algorithms of Your Disease Risk (www.yourdiseaserisk.wustl.edu; Appendix B). ${ }^{9,10}$

\section{Outcome Measures}

Outcome assessment included:

1. whether at their last PCP visit they talked about risk of developing diseases in the future, changes to improve health, and speaking to a genetic counselor (only for high-risk individuals);

2. improvement in accuracy of self-perceived versus calculated risk for individuals with inaccurate risk perception before the visit (both selfperceived and calculated risks were categorized as "average," including below average or average versus "high" risk. Self-perceived risk was considered inaccurate if self-perceived risk did not match calculated risk. Improvement in accuracy was defined as accurate self-perceived risk postvisit if it had been inaccurate pre-visit); and

3. whether women aged $\geq 40$ years talked with their PCP about getting a mammogram in the next year.

\section{Statistical Analysis}

Logistic regression models with generalized estimating equations clustered on clinic, adjusted for age and patient characteristics that differed between the intervention and control groups. Statistical significance at $p<0.01$ accounted for multiple comparisons.

\section{Results}

Contact was attempted with 31,223 individuals (Appendix C). Sample demographics are shown in Table 2.

Intervention was associated with a trend toward patients reporting greater likelihood to have discussed risk of developing a disease with their PCP (54.1\% vs $45.5 \%$, AOR=1.34, 99\% $\mathrm{CI}=0.97,1.85$ ) and was significantly associated with discussion of changes to improve their health $(78.5 \%$ vs $74.1 \%, \mathrm{AOR}=1.67,95 \% \mathrm{CI}=1.07,2.60)$ (Table 3). Discussion of referral to a genetic counselor among those at high risk did not differ between intervention and control groups. 
Intervention was associated with greater improvement in accuracy of self-perceived risk following the PCP visit for diabetes $(16.0 \%$ vs $12.6 \%, \mathrm{AOR}=1.31,95 \% \mathrm{CI}=1.02,1.69)$ and colorectal cancer $(27.9 \%$ vs $17.2 \%, \mathrm{AOR}=1.83,95 \% \mathrm{CI}=1.25,2.68)$, with a similar trend for coronary heart disease $(23.1 \%$ vs $18.3 \%, \mathrm{AOR}=1.29,95 \% \mathrm{CI}=0.95,1.75)$ and breast cancer $(21.0 \%$ vs $15.9 \%, \mathrm{AOR}=1.39,95 \% \mathrm{CI}=0.97,2.00)$ (Table 3$)$.

Women were fairly adherent with mammography screening (68.3\% had documented screening in the prior year). Intervention was not associated with plans to receive a mammogram in the coming year among women aged 40-75 years or among subgroups aged $40-49$ or 50-75 years. A trend toward greater discussion of whether a woman should receive a mammogram was observed for controls $(85.7 \%$ vs $88.7 \%$, AOR $=0.77,95 \% \mathrm{CI}=0.57$, $1.03)$.

\section{Discussion}

Systematic, pre-visit use of a multi-condition, EHR-integrated HRA in primary care has the potential to modestly improve patient-provider communication and patient understanding of personal health risk, by linking patient-provided information with their healthcare team and providing personalized education, reminders, and health tips. ${ }^{6,7}$ No evidence was generated for changes in discussion of plans for mammography, perhaps because this population was fairly adherent with mammography at baseline.

Though the literature is mixed on HRA effectiveness in primary care, $6,7,11$ this study is one of the few to examine an HRA integrated with an EHR. The approach was also "holistic," addressing risk across several common conditions. The approach is a strength for primary care, particularly because several factors convey risk for more than one condition, although this approach may dilute disease-specific messages. My Wellness Portal is a web-based personal health record that supports the delivery of preventive health services and includes a patient wellness plan and reminds patients about recommended preventive services, but is not integrated with decision support in an EHR; this personal health record was associated with improved timely receipt of preventive services. ${ }^{12}$ A pragmatic trial of a free-standing, breast cancer-focused risk assessment tool in primary care found improvements in discussion of breast cancer risk and also speaking with a genetic counselor. ${ }^{13}$ Several platforms assess risk based on family history alone. ${ }^{14,15}$ A pragmatic trial of web-based Family Healthware was associated with improvements in risk perception, and modest increases in self-reported physical activity and fruit and vegetable intake, but a reduced likelihood of receiving cholesterol screening. ${ }^{16}$

\section{Limitations}

Although PREP only reached $20 \%$ of potentially eligible individuals, implementation as part of a care plan could have higher participation. Even small effects can lead to substantive health improvement at the population level. Despite limitations, the PREP design informs the effectiveness of using patient-reported outcomes in primary care. Longer follow-up is needed to assess the impact of this HRA on health behaviors, and use of services. 


\section{Conclusions}

Integration of HRAs with EHRs offer the potential to improve the impact of HRAs. Access to a web-based portal, where patients could examine the effect of changes in lifestyle on risk, may promote behavior change, particularly if linked to assistance programs. ${ }^{17}$ Several trends in primary care, including population management, ${ }^{18}$ offer potential for greater integration of HRAs to promote healthier lifestyles, and personalized screening and management.

The widespread dissemination of EHRs that utilize a personal health record offers the potential to broaden population-based risk assessment, and promote communication and risk perceptions that may lead to more-personalized health prevention.

\section{Supplementary Material}

Refer to Web version on PubMed Central for supplementary material.

\section{Acknowledgments}

All funding sources for all authors are as follows: 5R18HS018644 from the Agency for Healthcare Research and Quality and U54CA163307 from the National Cancer Institute Population-based Research Optimizing Screening through Personalized Regimens initiative. The study sponsor had no role in study design; collection, analysis, and interpretation of data; writing the report; or the decision to submit the report for publication.

\section{References}

1. Yach D, Hawkes C, Gould CL, Hofman KJ. The global burden of chronic diseases: overcoming impediments to prevention and control. JAMA. 2004; 291(21):2616-2622. http://dx.doi.org/ 10.1001/jama.291.21.2616. [PubMed: 15173153]

2. Yoon PW, Scheuner MT, Peterson-Oehlke KL, Gwinn M, Faucett A, Khoury MJ. Can family history be used as a tool for public health and preventive medicine? Genet Med. 2002; 4(4):304-310. http:// dx.doi.org/10.1097/00125817-200207000-00009. [PubMed: 12172397]

3. Wang C, O'Neill SM, Rothrock N, et al. Comparison of risk perceptions and beliefs across common chronic diseases. Prev Med. 2009; 48(2):197-202. http://dx.doi.org/10.1016/j.ypmed.2008.11.008. [PubMed: 19073208]

4. Sabatino SA, McCarthy EP, Phillips RS, Burns RB. Breast cancer risk assessment and management in primary care: provider attitudes, practices, and barriers. Cancer Detect Prev. 2007; 31(5):375383. http://dx.doi.org/10.1016/j.cdp.2007.08.003. [PubMed: 18037249]

5. Acheson LS, Wiesner GL, Zyzanski SJ, Goodwin MA, Stange KC. Family history-taking in community family practice: implications for genetic screening. Genet Med. 2000; 2:180-185. http:// dx.doi.org/10.1097/00125817-200005000-00004. [PubMed: 11256663]

6. Baghelai, C.; Nelkin, VS.; Miller, TR. Health Risk Appraisals in Primary Care:Current Knowledge and Potential Applicationsn To Improve Preventive Services and Chronic Care. Rockville, MD: Agency for Healthcare Research \& Quality; 2009.

7. Kreuter MW, Strecher VJ. Changing inaccurate perceptions of health risk: results from a randomized trial. Health Psychol. 1995; 14(1):56-63. http://dx.doi.org/10.1037/0278-6133.14.1.56. [PubMed: 7737074]

8. Onega T, Beaber EF, Sprague BL, et al. Breast cancer screening in an era of personalized regimens: A conceptual model and National Cancer Institute initiative for risk-based and preference-based approaches at a population level. Cancer. 2014; 120(19):2955-2964. http://dx.doi.org/10.1002/cncr. 28771. [PubMed: 24830599] 
9. Colditz GA, Atwood KA, Emmons K, et al. Harvard report on cancer prevention volume 4: Harvard Cancer Risk Index. Cancer Causes Control. 2000; 11(6):477-488. http://dx.doi.org/10.1023/A: 1008984432272. [PubMed: 10880030]

10. Kim DJ, Rockhill B, Colditz GA. Validation of the Harvard Cancer Risk Index: a prediction tool for individual cancer risk. J Clin Epidemiol. 2004; 57(4):332-340. http://dx.doi.org/10.1016/ j.jclinepi.2003.08.013. [PubMed: 15135833]

11. Wagner EH, Beery WL, Schoenbach VJ, Graham RM. An assessment of health hazard/health risk appraisal. Am J Public Health. 1982; 72(4):347-352. http://dx.doi.org/10.2105/AJPH.72.4.347. [PubMed: 7065313]

12. Nagykaldi ZJ, Voncken-Brewster V, Aspy CB, Mold JW. Novel computerized health risk appraisal may improve longitudinal health and wellness in primary care: a pilot study. Appl Clin Inform. 2013; 4(1):75-87. http://dx.doi.org/10.4338/ACI-2012-10-RA-0048. [PubMed: 23650489]

13. Kaplan CP, Livaudais-Toman J, Tice JA, et al. A randomized, controlled trial to increase discussion of breast cancer in primary care. Cancer Epidemiol Biomarkers Prev. 2014; 23:1245-1253. http:// dx.doi.org/10.1158/1055-9965.EPI-13-1380. [PubMed: 24762560]

14. Wang C, Sen A, Ruffin MT, et al. Family history assessment: impact on disease risk perceptions. Am J Prev Med. 2012; 43(4):392-398. http://dx.doi.org/10.1016/j.amepre.2012.06.013. [PubMed: 22992357]

15. Orlando LA, Wu RR, Beadles C, et al. Implementing family health history risk stratification in primary care: impact of guideline criteria on populations and resource demand. Am J Med Genet C Semin Med Genet. 2014; 166(1):24-33. http://dx.doi.org/10.1002/ajmg.c.31388.

16. Ruffin MT, Nease DE Jr, Sen A, et al. Effect of preventive messages tailored to family history on health behaviors: the Family Healthware Impact Trial. Ann Fam Med. 2011; 9(1):3-11. http:// dx.doi.org/10.1370/afm.1197. [PubMed: 21242555]

17. Haas JS, Linder JA, Park ER, et al. Proactive tobacco cessation outreach to smokers of low socioeconomic status: a randomized clinical trial. JAMA Intern Med. 2015; 175(2):218-226. http://dx.doi.org/10.1001/jamainternmed.2014.6674. [PubMed: 25506771]

18. Chen EH, Bodenheimer T. Improving population health through team-based panel management: comment on "Electronic medical record reminders and panel management to improve primary care of elderly patients". Arch Intern Med. 2011; 171(17):1558-1559. http://dx.doi.org/10.1001/ archinternmed.2011.395. [PubMed: 21949164] 


\section{Table 1}

Study Flow

\begin{tabular}{|c|c|}
\hline Intervention & Control \\
\hline \multicolumn{2}{|c|}{ Assessment 4 weeks before primary care provider $(\mathrm{PCP})$ visit } \\
\hline \multicolumn{2}{|l|}{$\begin{array}{l}\text { - Collection of risk factors and } \\
\text { calculation of risk }\end{array}$} \\
\hline - Self-perceived risk & - Self-perceived risk only \\
\hline $\begin{array}{l}\text { - Health risk appraisal (HRA) with } \\
\text { personalized recommendations sent to } \\
\text { patient }\end{array}$ & - No risk HRA to patient \\
\hline - Coded risk factor data sent to PCP & - No coded risk factor data to PCP \\
\hline \multicolumn{2}{|c|}{ PCP visit } \\
\hline \multicolumn{2}{|c|}{ Assessment 2 to 4 weeks after PCP visit } \\
\hline & $\begin{array}{l}\text { - Collection of risk factors and } \\
\text { calculation of risk }\end{array}$ \\
\hline - Self-perceived risk & - Self-perceived risk \\
\hline \multirow[t]{3}{*}{ - Outcome Assessment } & - Outcome assessment \\
\hline & $\begin{array}{l}\text { - HRA with personalized } \\
\text { recommendations sent to patient }\end{array}$ \\
\hline & - No coded risk factor data to PCP \\
\hline
\end{tabular}


Table 2

Study Population

\begin{tabular}{|c|c|c|c|}
\hline Characteristics & $\begin{array}{c}\text { Intervention } \\
\mathbf{N}(\%)\end{array}$ & $\begin{array}{l}\text { Control } \\
\mathrm{N}(\%)\end{array}$ & $p$-value \\
\hline $\mathrm{N}$ & 1,699 & 2,004 & \\
\hline Median age, years & 55 & 56 & 0.18 \\
\hline \multicolumn{4}{|l|}{ Sex } \\
\hline Female & $1,338(78.8)$ & $1,415(70.6)$ & $<0.0001$ \\
\hline \multicolumn{4}{|l|}{ Race/ethnicity } \\
\hline White & $1,418(83.5)$ & $1,675(83.6)$ & 0.78 \\
\hline Black & $79(4.7)$ & $82(4.1)$ & \\
\hline Latino & $91(5.4)$ & $105(5.2)$ & \\
\hline Other/unknown & $111(6.5)$ & $142(7.1)$ & \\
\hline Married & $1,101(64.8)$ & $1,456(72.7)$ & $<0.0001$ \\
\hline \multicolumn{4}{|l|}{ Insurance } \\
\hline Private & $1,231(72.5)$ & $1,435(71.6)$ & 0.7995 \\
\hline Medicare & $358(21.1)$ & $430(21.5)$ & \\
\hline Medicaid/uninsured & $110(6.4)$ & $139(6.9)$ & \\
\hline \multicolumn{4}{|l|}{ BMI category } \\
\hline Normal/underweight & $751(44.3)$ & $725(36.3)$ & $<0.0001$ \\
\hline Overweight & $541(31.9)$ & $729(36.5)$ & \\
\hline Obese & $404(23.8)$ & $545(27.3)$ & \\
\hline \multicolumn{4}{|l|}{ Smoking status } \\
\hline Current & $56(3.3)$ & $90(4.5)$ & $<0.0001$ \\
\hline Former & $356(21.0)$ & $557(27.8)$ & \\
\hline Never & $1,287(75.8)$ & $1,357(67.7)$ & \\
\hline $\begin{array}{l}\text { Prior personal history of } \\
\text { Diabetes }\end{array}$ & $145(8.5)$ & $173(8.6)$ & 0.9153 \\
\hline Coronary heart disease & $129(7.6)$ & $189(9.4)$ & 0.0466 \\
\hline Colorectal cancer & $21(1.2)$ & $25(1.3)$ & 0.9749 \\
\hline Breast cancer (women only) & $107(8.0)$ & $118(8.3)$ & 0.7432 \\
\hline \multicolumn{4}{|l|}{ Charlson score } \\
\hline 0 & $1,514(89.1)$ & $1,828(91.2)$ & 0.0285 \\
\hline 1 & $118(7.0)$ & $98(4.9)$ & \\
\hline $2+$ & $67(3.9)$ & $78(3.9)$ & \\
\hline \multicolumn{4}{|l|}{ High risk for developing } \\
\hline Diabetes & $232(13.7)$ & $357(17.8)$ & 0.0022 \\
\hline Coronary heart disease & $117(6.9)$ & $167(8.3)$ & 0.0258 \\
\hline Colorectal cancer & $225(13.2)$ & $332(16.6)$ & 0.0179 \\
\hline Breast cancer (women only) & $251(18.8)$ & $246(17.4)$ & 0.6322 \\
\hline \multicolumn{4}{|c|}{ Pre-visit self-perceived risk inaccurate } \\
\hline Coronary heart disease & $804(51.2)$ & $777(42.8)$ & $<0.0001$ \\
\hline Diabetes & $1,017(65.4)$ & $1,112(60.7)$ & 0.0047 \\
\hline
\end{tabular}




\begin{tabular}{lccc}
\hline Characteristics & Intervention & Control & $p$-value \\
& $\mathbf{N}(\%)$ & $\mathbf{N}(\%)$ & \\
\hline Colorectal cancer & $865(51.3)$ & $928(46.9)$ & $\mathbf{0 . 0 0 5}$ \\
Breast cancer (women only) & $675(54.8)$ & $648(50.0)$ & $\mathbf{0 . 0 1 4 2}$ \\
\hline
\end{tabular}

Note: Boldface indicates statistical significance $(p<0.05)$. 


\section{름}

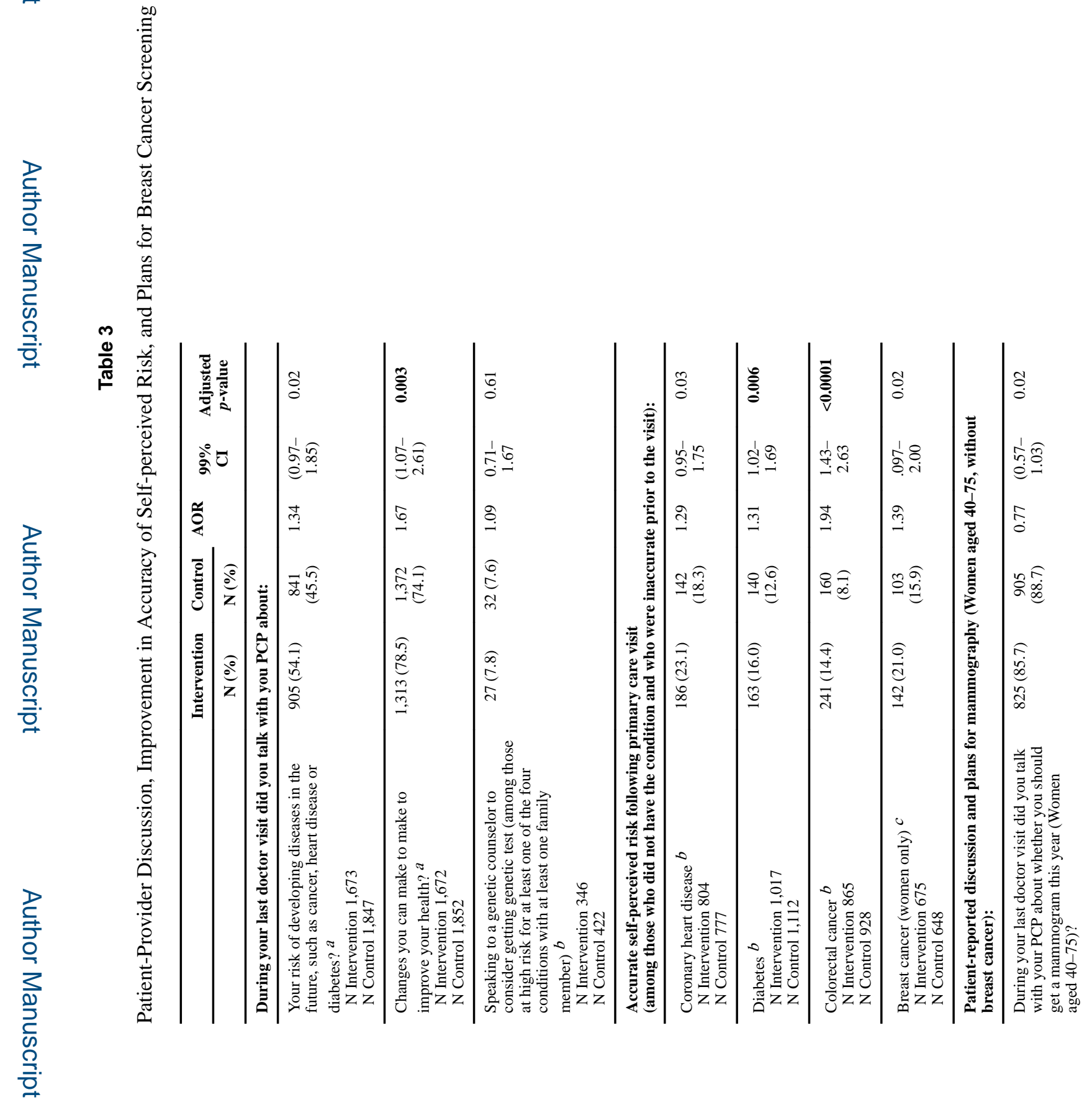

Am J Prev Med. Author manuscript; available in PMC 2018 January 01. 

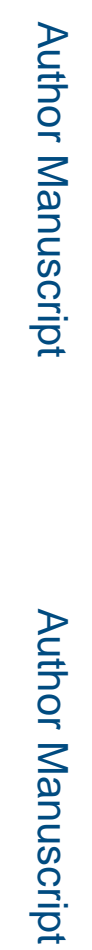

룰

을

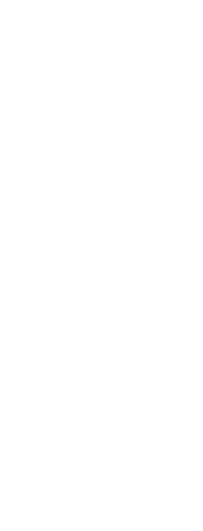

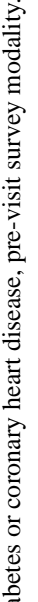

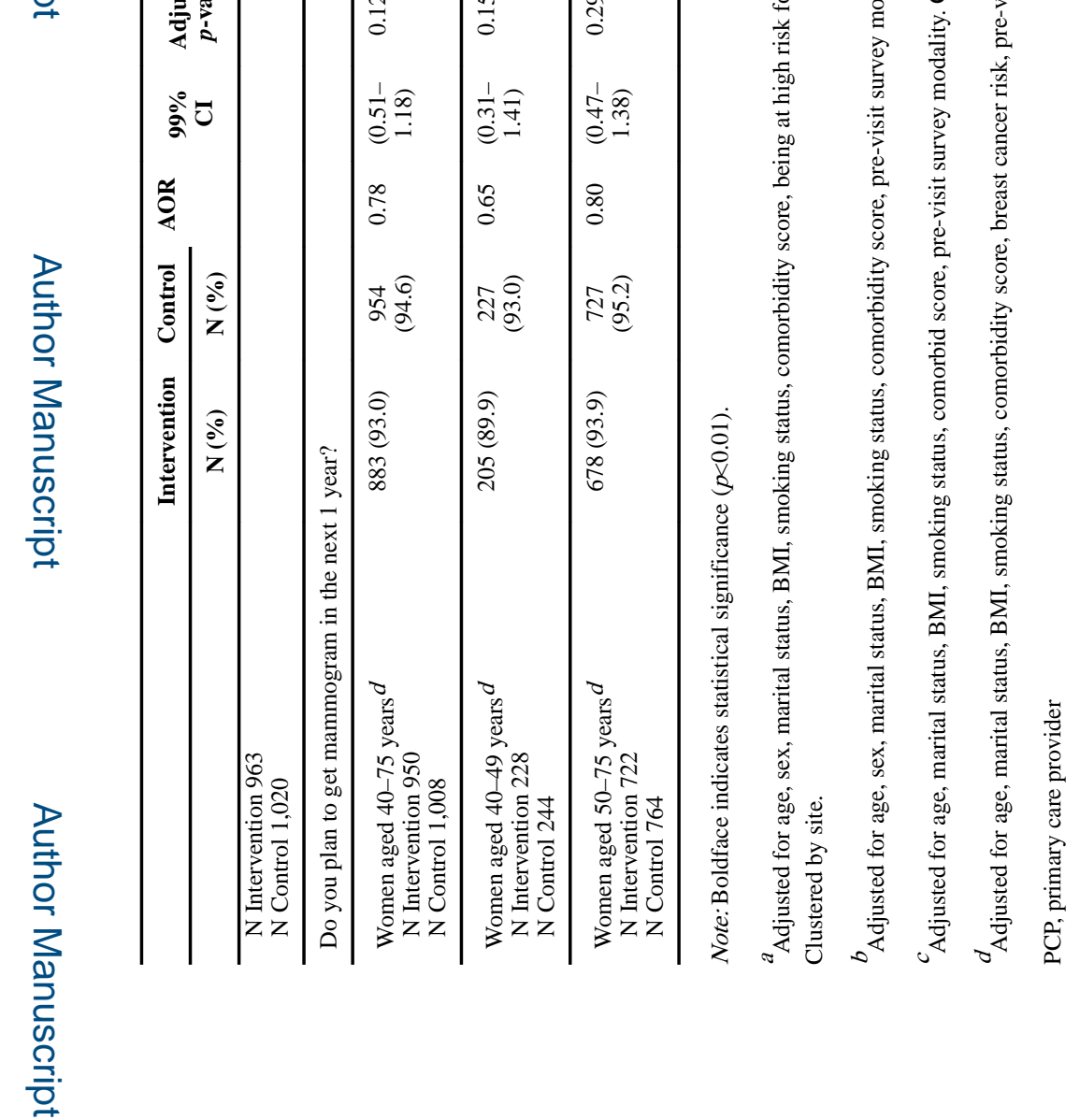

Am J Prev Med. Author manuscript; available in PMC 2018 January 01. 